\title{
Pain in older persons
}

\author{
Thomas Hadjistavropoulos PhD, Guest Editor
}

$\mathrm{I}$ $\mathrm{t}$ gave me great pleasure to accept the invitation to serve as guest editor for this special issue, which recognizes the International Association for the Study of Pain (IASP) Global Year Against Pain in Older Persons. In 2001, I had the pleasure of guest editing another special issue of Pain Research 8 Management on Pain and Aging. My 2001 editorial (1) recognized the increasing interest that researchers and clinicians were showing in the topic of pain in older adults, and pointed out as evidence of that interest the efforts to create an IASP Special Interest Group on Pain in Older Persons, the publication of several related volumes (2-4) and the United States Joint Commission on Accreditation of Health Care Organisations guidelines for assessing geriatric pain (5).

We have come such a long way in the six years that have passed since the 2001 special issue. The IASP Special Interest Group on Pain in Older Persons is now well established and the IASP has named 2006/2007 as its Global Year Against Pain in Older Adults. In addition, specialized and up-to-date volumes on the topic continue to be published $(6,7)$ and tremendous progress has been made in both the areas of pain assessment (6,8-10) and management (6).

The present issue of Pain Research $\mathcal{E}$ Management is well balanced. The contributing authors represent a variety of clinical and research disciplines (eg, nursing, medicine and clinical psychology). Two of the four original papers $(11,12)$ are empirical while the other two $(13,14)$ are systematic literature reviews. Two papers focus primarily on older adults residing in long-term care facilities $(11,13)$, one paper focuses on palliative care (14) and one on seniors undergoing total knee arthroplasty (12). This special issue also includes a review of the book Clinical Management of the Elderly Patient in Pain (7). The

\section{REFERENCES}

1. Hadjistavropoulos T. Pain and aging. Pain Res Manag 2001;6:116-7.

2. Roberto KA, Gold DT. Chronic Pain in Later Life: A Selectively Annotated Bibliography. Westport: Greenwood Press, 2001.

3. Ferrell BR, Ferrell BA, eds. Pain in the Elderly. Seattle: International Association for the Study of Pain, 1996.

4. Roy R, ed. Chronic Pain in Old Age: An Integrated Biopsychosocial Perspective. Toronto: University of Toronto Press, 1995.

5. Comprehensive Accreditation Manual for Long Term Care (Dementia and Subacute Included). Oakbrook Terrace: Joint Commission on Accreditation of Health Care Organizations, 2000.

6. Gibson SJ, Weiner D, eds. Pain in the Elderly. Seattle: International Association for the Study of Pain, 2005.

7. McCleane G, Smith H, eds. Clinical Management of the Elderly Patient in Pain. Binghampton, New York: The Haworth Press, 2006.

8. Zwakhalen SM, Hamers JP, Abu-Saad HH, Berger MP. Pain in elderly people with severe dementia: A systematic review of behavioural pain assessment tools. BMC Geriatr 2006;6:3.

9. Zwakhalen SM, Hamers JP, Berger MP. The psychometric quality and clinical usefulness of three pain assessment tools for elderly people with dementia. Pain 2006;126:210-20. review was prepared by Romayne Gallagher. Last but not least, Laurence Jerome contributed a case study of an older woman with a 20-year history of vulvodynia (15).

The paper by Lucia Gagliese and colleagues (14) helps clarify some of the questions that exist concerning age-related patterns in the relationship between cancer pain and depression. The study by Maya Roth et al (12) helps fill a gap in the literature by examining some of the psychosocial determinants of acute postoperative total knee arthroplasty pain among seniors. In the area of long-term care, the investigation by Sandra Zwakhalen and colleagues (11) provides evidence of knowledge gaps among nursing staff. Such knowledge gaps often relate to insufficient information about assessment tools that have been specifically designed for older persons who have limited ability to communicate due to dementia (16). Systematic information comparing such specialized assessment tools is needed not only by clinicians but also by researchers. Information allowing comparisons across pain assessment tools for patients with dementia is provided by Michèle Aubin and colleagues (13). The Aubin et al article also marks an important milestone for the Journal because it is written in French. Although Pain Research 83 Management has the mandate to publish papers in both French and English, this is the first time that a paper in French has been published. I thank the Editorin-Chief of Pain Research $\mathcal{E}$ Management, Dr Kenneth D Craig, for encouraging this initiative.

I extend thanks to all contributors for their important work in this area, and for sharing their findings and ideas with the 18,000 readers of Pain Research $\mathcal{E}$ Management (the journal of the Canadian Pain Society). I also extend my thanks to Kenneth D Craig for the opportunity to guest edit this special issue.

10. Hadjistavropoulos T, Herr K, Turk DC, et al. An interdisciplinary expert consensus statement on assessment of pain in older persons. Clin J Pain 2007;23(Suppl 1):S1-43.

11. Zwakhalen SM, Hamers JP, Peijnenburg RH, Berger MP. Nursing staff knowledge and beliefs about pain in elderly nursing home residents with dementia. Pain Res Manag 2007;12:177-84.

12. Roth ML, Tripp DA, Harrison MH, Sullivan M. Demographic and psychosocial predictors of acute perioperative pain for total knee arthroplasty. Pain Res Manag 2007;12:185-194.

13. Aubin M, Giguère A, Hadjistavropoulos T, Verreault R. Évaluation systématique des instruments pour mesurer la douleur chez les personnes âgées ayant des capacités réduites à communiquer. Pain Res Manag 2007:12:195-203.

14. Gagliese L, Gauthier LR, Rodin G. Cancer pain and depression: A systematic review of age-related patterns. Pain Res Manag 2007;12:205-11.

15. Jerome L. Pregabalin-induced remission in a 62-year-old woman with a 20-year history of vulvodynia. Pain Res Manage 2007;12:212-4.

16. Martin R, Williams J, Hadjistavropoulos T, Hadjistavropoulos HD, MacLean M. A qualitative investigation of seniors' and caregivers' views on pain assessment and management. Can J Nurs Res 2005;37:142-64.

Department of Psychology and Centre on Aging and Health, University of Regina, Regina, Saskatchewan

Correspondence: Dr Thomas Hadjistavropoulos, Department of Psychology and Centre on Aging and Health, University of Regina, Room 338, 3737 Wascana Parkway, Regina, Saskatchewan S4S 0A2. Telephone 306-585-4457, e-mail Thomas.Hadjistavropoulos@uregina.ca 


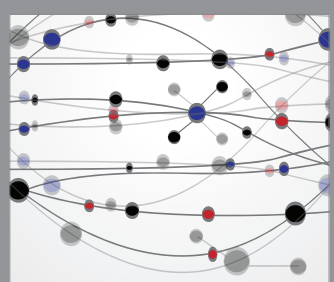

The Scientific World Journal
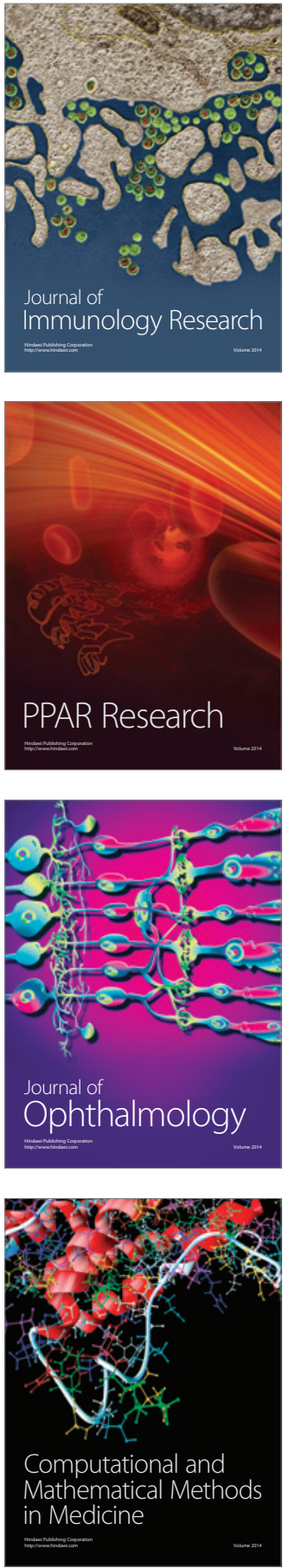

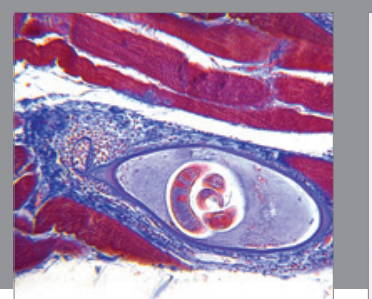

Gastroenterology Research and Practice

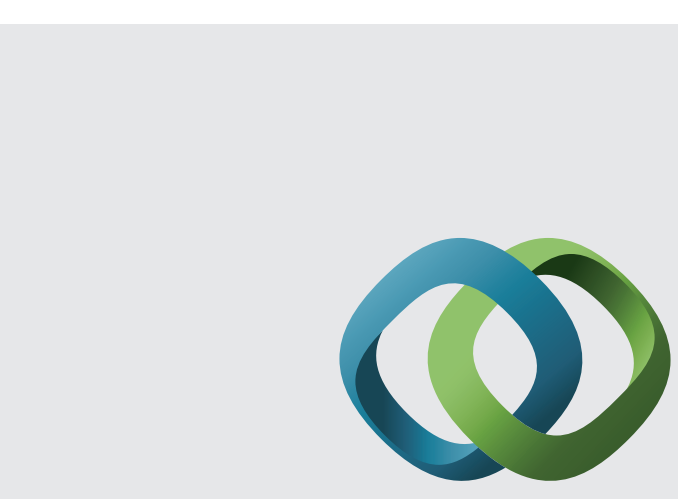

\section{Hindawi}

Submit your manuscripts at

http://www.hindawi.com
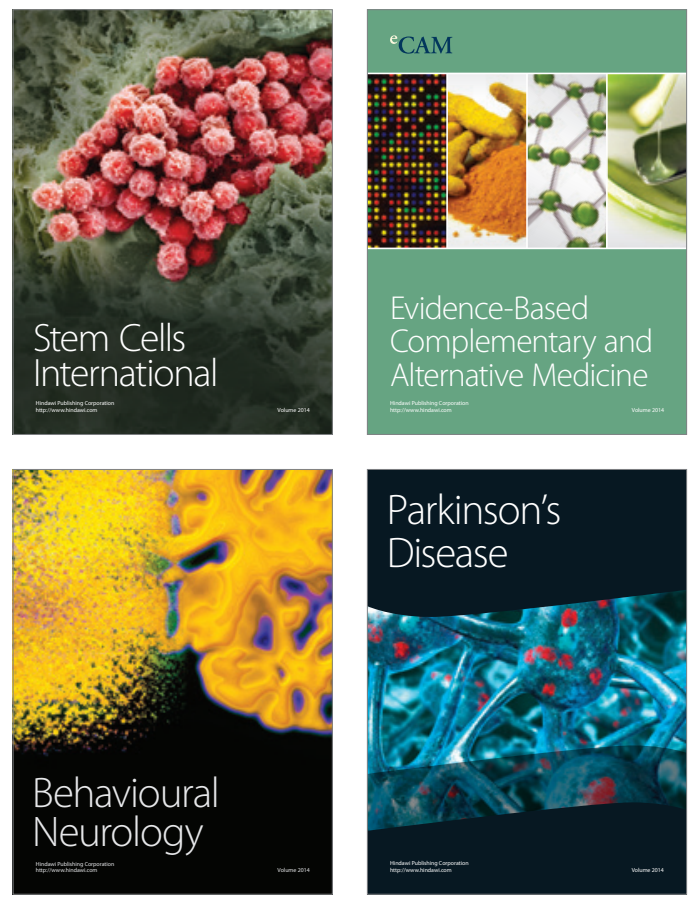
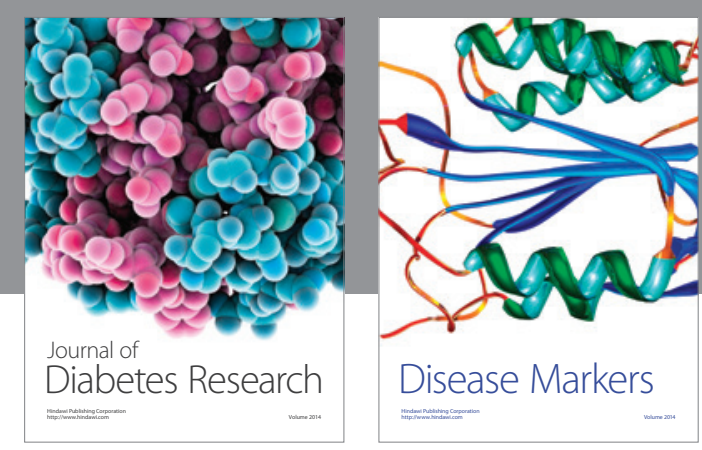

Disease Markers
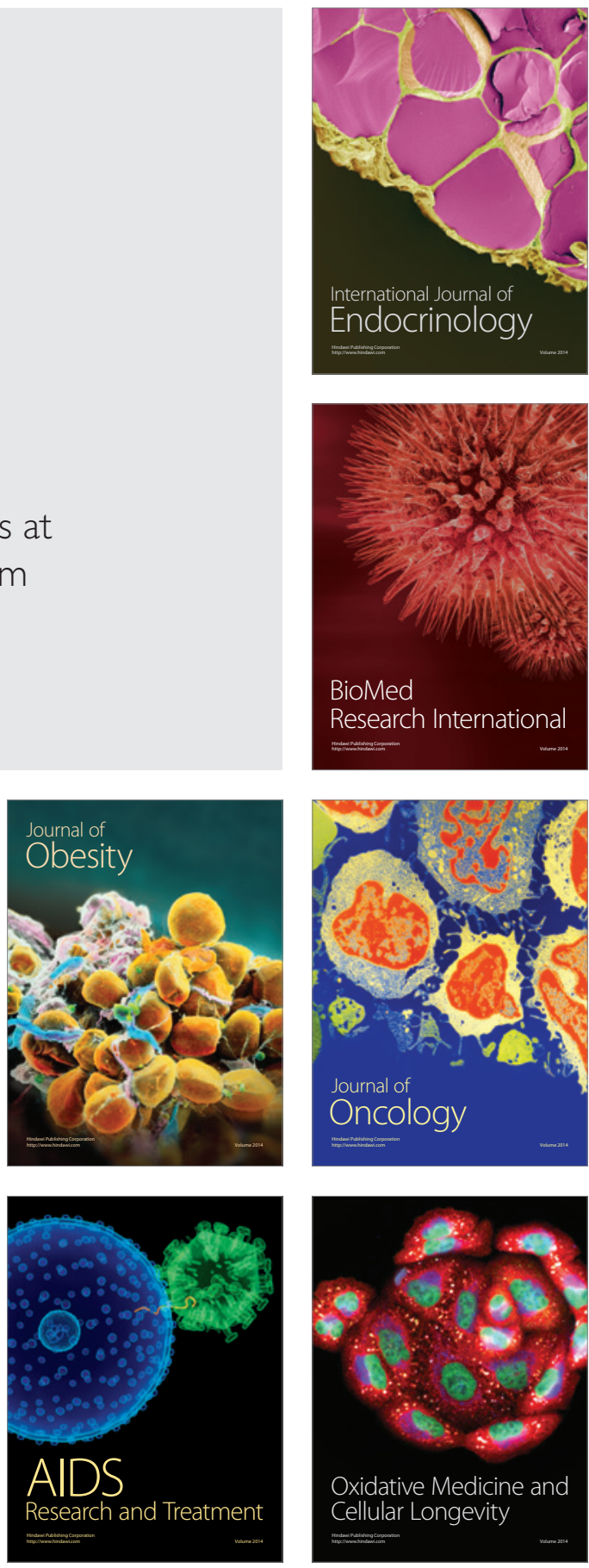